\title{
Innovative, Participatory Listening and Seeing Experiences in Museums
}

\author{
Tobias Ziegler \\ TAMSCHICK MEDIA\&SPACE \\ Buelowstrasse 66, 10783 Berlin \\ Germany \\ tobias@bureau18.de
}

\begin{abstract}
Not only recently in the age of "new media", museums have utilised different types of "media" to open the world behind the artefacts and objects on display. But now, with sheer endless possibilities at hand and constantly new emerging technologies, it is up to the curators, scenographers, artists, directors and other players involved to orchestrate the means at their hands to create a sustainable and enduring museum experience.
\end{abstract}

Most of the visitors know the different types of media very well. People of all ages are used to surf on the internet, to use touch-devices or simply know how to navigate between different TVprograms. Narrative storytelling is widely common. But when it comes to utilising media and stateof-the-art technology, many museums still rely on the multi-media terminal right before the gift shop. But much more is possible. The potential lies in creating situations, environments or atmospheres in which visitors can immerse into the world of the facts and stories of an exhibition

Based on selected case studies, the paper will try to show different strategies how digital audiovisual media-based narratives can be used to open the fascinating worlds behind the objects and artefacts.

Interactive. Multimedia. Augmented reality. Media installation. Immersive installation. Media scenography. Museum.

\section{INTRODUCTION}

Electronic media have become an integrative part of the museum in the 21 st century. Exhibitions without linear, audio-visual narratives displayed on common screens or interactive information kiosks are almost unimaginable. And the range of possibilities is constantly evolving, with the creativity forming the only limit. Curators, scenographers, media designers have the necessary means at their hands to develop new tools for the mediation of knowledge and information in museums. These new tools, which in some cases visitors utilise in their everyday life, also have the potential to help to create a deeper and more enduring and immediate experience in exhibitions.

Especially during the last two decades, the aforementioned developments gave rise to numerous new concepts and applications that have been implemented in museum throughout the world. But a profound and holistic scientific classification is yet to be done.
The following chapters will look at two different concepts that have been used in different exhibitions. In the first chapter, the discussion is focussing on digital-media-based stagings of original objects and artefacts. The second chapter takes a closer look on digital-media-based environments dealing with abstract stories or topics.

The discussed projects have all been realised by or in cooperation with the Berlin based company TAMSCHICK MEDIA+SPACE. The author was working for this company and therefore has a deep insight in the projects and the underlying concepts.

\section{ABOUT BREAKING TABOOs - AUGMENTED ARTEFACTS}

Although the many types of contemporary digitalmedia enter the world of the museums, artefacts and original objects are still constituent and the main object for understanding in cultural history exhibitions (Vieregg 2006, Waidacher 2004). But the inherent meaning and significance cannot always be deciphered through simply looking at the object. The different aspects and layers need to be 
communicated in order to enable the visitors to understand the information lying behind the object (Vieregg 2006).

One of the big taboos in the work for exhibitions showing original objects and artefacts is still to let the objects free from any augmentation or direct overlay through audio-visual media. The following projects show different ways how a precisely designed media scenography can enhance the narrative space of original objects and artefacts and open a sensual and direct connection to the different layers of information - even by breaking the taboo.

\subsection{Experiencing the precious - Museum for Textile and Industry Augsburg (Germany)}

The Museum for Textile and Industry in Augsburg has a section showcasing 200 years of textiles, design, fashion and industry from the region. The probably most important objects are 550 pattern books containing more than 1.3 million samples of patterns in different sizes used for textile printing. They are the core of the exhibition that was designed by ATELIER BRÜCKNER. The challenge for the curators, scenographers, directors and designers was to make the unique content of the books - patterns, shapes, colours from three centuries (starting in 1780) - accessible to the public.

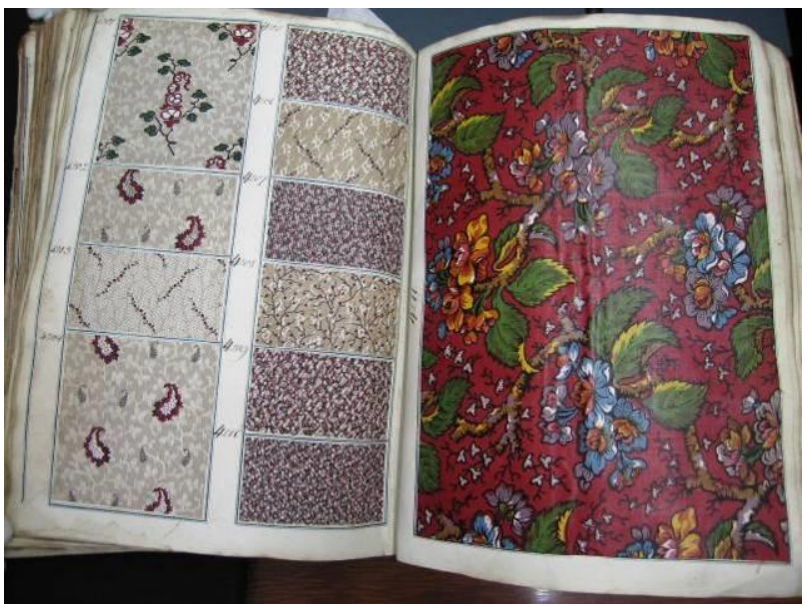

Figure 1: Historic pattern book containing small and large scale pattern samples for textiles (C) Tamschick Media+Space)

The installation is consisting of three largerfigurines, the so called Graces (placed in the centre of the space) and an interactive touch terminal next to them. The glass cabinets showcasing a selection of the pattern books are placed at the side of the room. Two of the Graces are fully covered by a video projection.

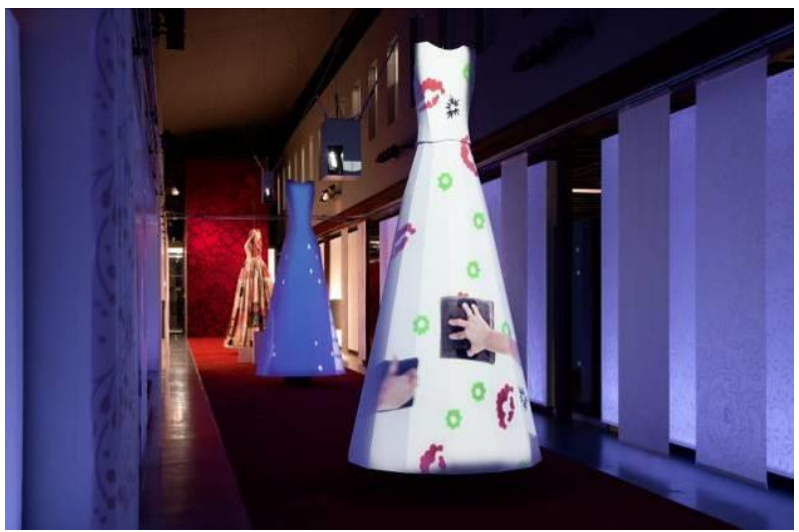

Figure 2: View of the exhibition space with the "3 Graces"(@ Zhümer)

Visitors are invited to explore a selection of hundreds of patterns by browsing through a digital pattern book on the touch terminal. Once a selection has been made, the pattern will be projected onto the figurines and create a digital dress. Alternatively, different patterns can also be combined to form one continuous multi-patterned dress. In addition, visitors can select informational sequences showing different printing techniques directly on the figurines.

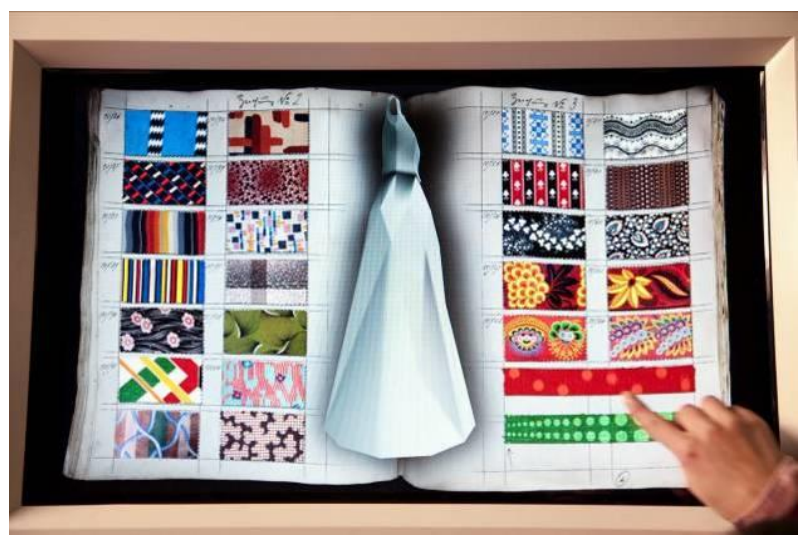

Figure 3: The digital pattern book in use (@ Zhümer)

The third grace is designed to be the haptic counterpart to the video-mapped figurines. Visitors are invited to touch the real larger-than-life sized dress consisting of different fabrics, designed by the artist Anja Luithle.

The original objects - the precious pattern books have a somewhat abstract character as they only show a small rectangular sample of the pattern and lie untouchable in glass cabinets. It is hard to imagine how what a specific pattern would like on a dress, with its pleats and general shape. 


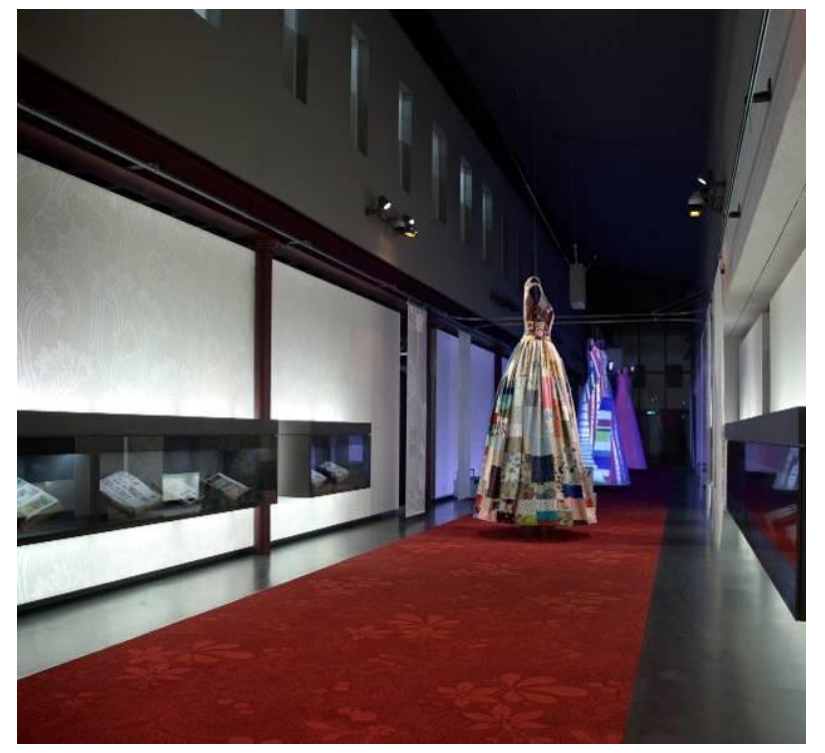

Figure 4: View of the exhibition space. Foreground: the wall mounted glass cabinets containing the original pattern books, Centre: Figurine with real dress, far end: video-mapped figurines (@ Zhümer)

This digital-media based installation makes the objects of interest (the pattern books) accessible by transferring the main content in a nearly immersive interactive experience for the visitors. Although the interactive panel is a one-at-a-time interface, two visitors can create digital dresses for each of the two media-mapped figurines one after another. All the other visitors in the space can experience the strong impression of the installation by gazing at the larger-than-life sized graces or by touching the third one.

\subsection{Breaking the taboo - Rhenisch State Museum Trier (Germany)}

The Rhenish State Museum in Trier possesses 15 monumental roman funerary monuments. These 2000-year-old stone artefacts are exhibited in room dedicated especially to them. They are considered to be an archaeological sensation as they are in very good condition. Their reliefs show different scenes from the everyday life in the Roman Empire (Koehne 2015). But without historical knowledge, the underlying stories and historical interrelations can only partially be decoded by reading the descriptions. The goal was, to create a mediabased staging that makes these 'hidden' information more easily and intuitively accessible to the visitors in an emotional and direct way.

In close cooperation, a team consisting of the museums curators and artists of different professions (under artistic supervision by Charlotte Tamschick) conceived a 45-minute long fictional narrative picking up the different stories that are displayed in the reliefs.

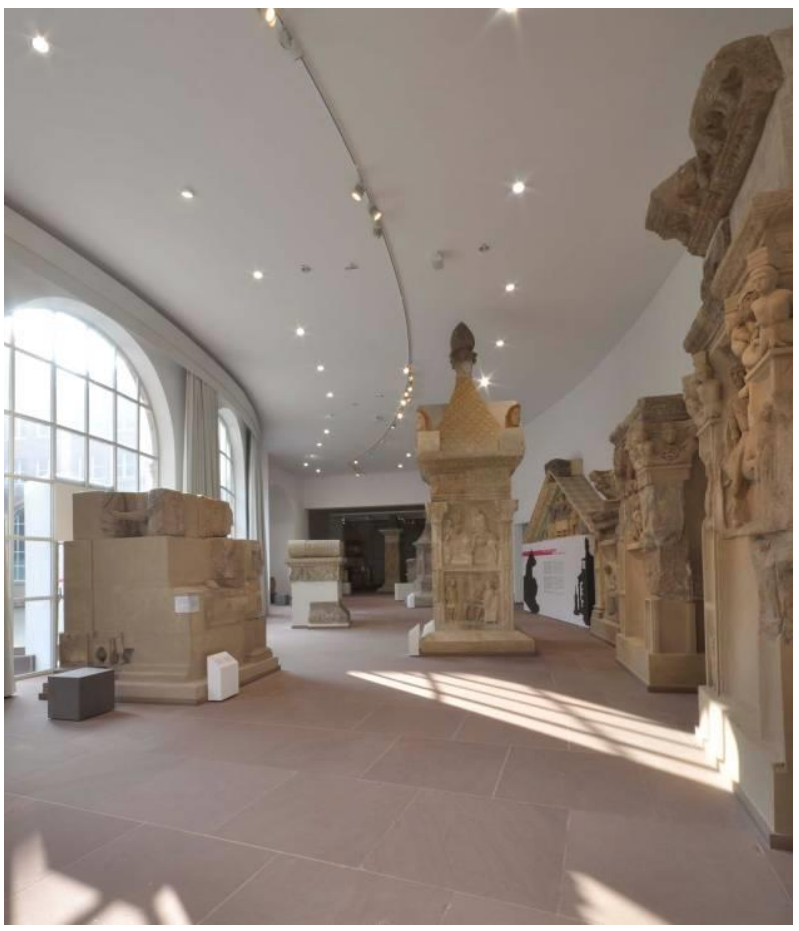

Figure 5: View of the exhibition space without any video mapping (@ Rheinisches Landesmuseum Trier)

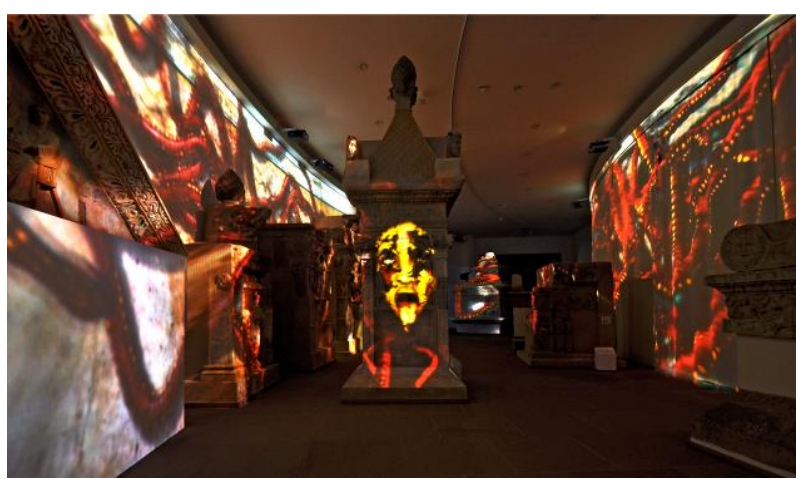

Figure 6: View of the exhibition space with video mapping (@ Zühmer)

This has then been translated into an audio drama with corresponding hand-drawn animated films, which were directly projected onto the exhibits and the walls of the exhibition space. The decision to use the funerary monuments and the reliefs as 'screens' was made consciously as each is superimposed by the projection only for a short period of time and only for the course of the presentation. Additionally visitors still have the chance to see the artefacts in their natural state with standard lighting in between the presentations. By combining the reliefs with the video projection, thus embedding the original object in the mediabased staging, the exhibits become integrative part of the narration. 


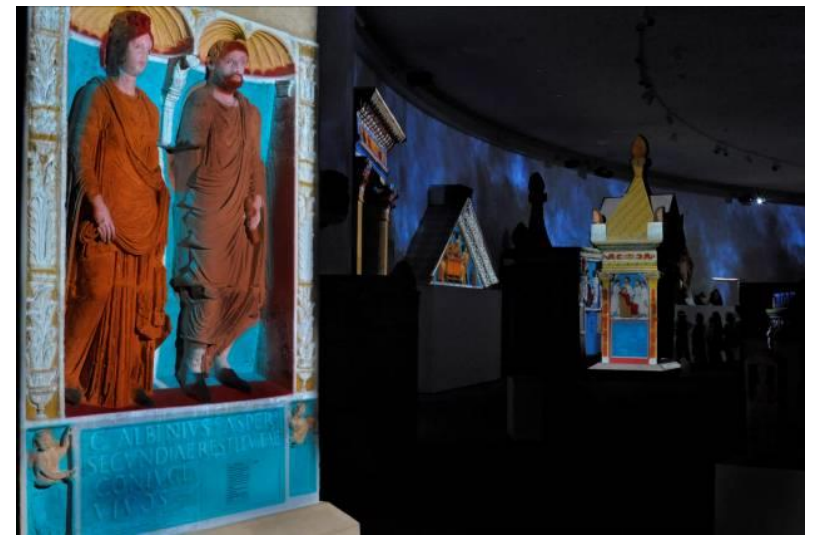

Figure 7: Close up of a funerary monument with video mapping (@ Zühmer)

The animated films are congruent with the reliefs and also give an idea of their colourful decorations that has faded over the centuries. The 45-minute spatial narrative brings up different aspects of the everyday life and intellectual world of the Romans, their relation to topics like death or afterlife. As one monument after the other is brought to life, visitors are invited to wander through the space and take a closer look at the ancient artefacts. The programme is shown several times a day. Therefore the space is separated from the rest of the exhibition and darkened. Visitors can move through the space free and follow the narration at their own pace.

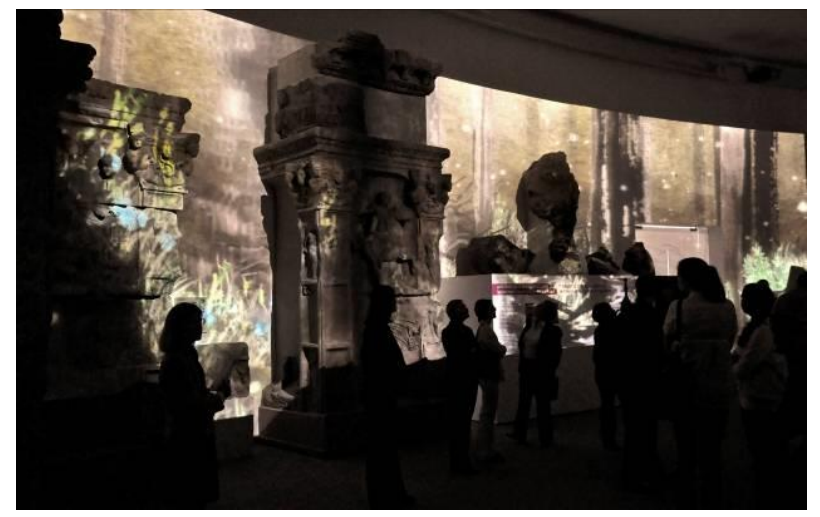

Figure 8: Visitors in the exhibition space surrounded by video projection (@ Zühmer)

The film sequences, visible on the exhibits and all walls in combination with the multi-channel audio drama and spatial sound-design create an environment that immerses the visitors into the narrative. The scenographic staging with its scripted and curated storyline makes multiple layers of abstract information more easily accessible for a broader public.

\subsection{Staged costumes - Fastnachtsmuseum Kitzingen (Germany)}

A similar strategy has been used in the renewed exhibition at the national carnival museum in
Kitzingen (Germany). Opened in 2013, the mediabased staging brings to live twelve historical, socalled Fastnachts-costumes (Fastnacht can be considered to be equivalent to the British Shrovetide (Merriam-Webster 2015)). In a small space the life-sized costumes are placed on a stage behind different layers of transparent gauze.

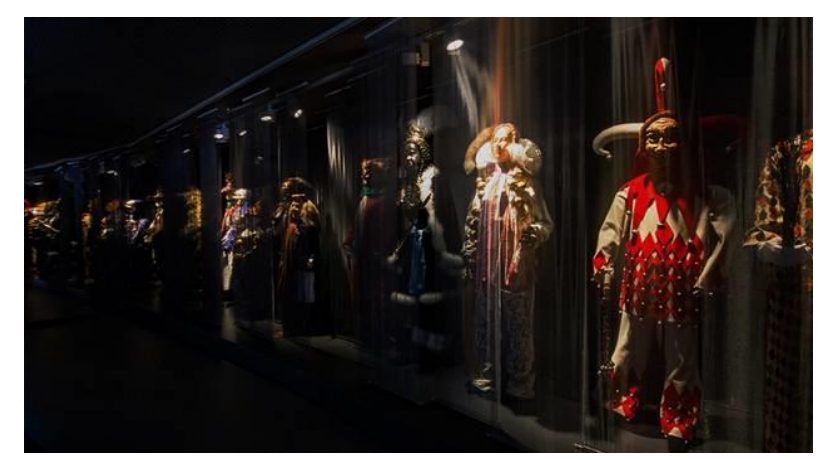

Figure 9: View of the exhibition space with costumes behind layers of gauze (C Lisa Rau / Tamschick Media+Space)

A projection consisting of live-action footage enriched with different graphical elements shows the characteristic dances, movements and behaviours of each costume. In regular intervals, each costume is lit to enable the visitors to look at the objects themselves. Again the augmentation of the original objects by superimposing digital-media reveals underlying information and makes it directly and emotional experienceable through creating an audio-visual narrative.

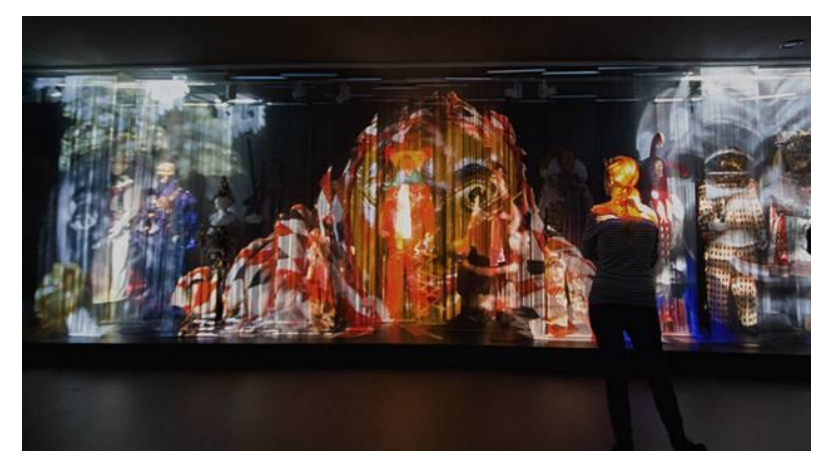

Figure 10: View of the stage with the video layer being projected onto the gauze (C Lisa Rau / Tamschick Media+Space)

\section{DIVING INTO THE STORY - IMMERSIVE PARTICIPATORY NARRATIVES IN MUSEUMS}

In these days, museums and cultural history exhibitions are dealing with more and more complex and multi-layered subjects and questions. Curators face the question how these complex interrelations and levels of meaning can be mediated to the visitors. The potential lying in digital-media of being the means to cope with this 
challenge has dramatically increased. The classic format of the rectangular display has been replaced by media canvasses in a multitude of shapes, sizes and spatio-temporal dimensions (Ventimiglia 2015). The discussion of the following two projects will show in different ways, how large-scale (digital \& interactive) media-based immersive scenographic concepts with different formats can be used to provide a deeper insight and understanding to the respective subject matters, thus providing a more enduring and sustainable museum experience.

\subsection{The Time Machine - Wu Kingdom Helü Relics Museum, Wuxi (PR China)}

At beginning of 2014, the Wu Kingdom Helü Relics Museum was opened to the public near the city of Wuxi. The main focus of the newly build complex and its exhibitions is on the story of the Kingdom of Wu and the ancient, disappeared city of Helü. Both existed during the Spring and Autumn Period - one of the important periods in ancient Chinese history. Visitors are invited to explore the 2,500-year-old history in different exhibition spaces, showcasing numerous artefacts and replicas. Besides having a museum close to the presumably authentic historic place, the curators wanted to make the legend in the core of the complex history accessible through an emotional and summarising multi-media based narrative.

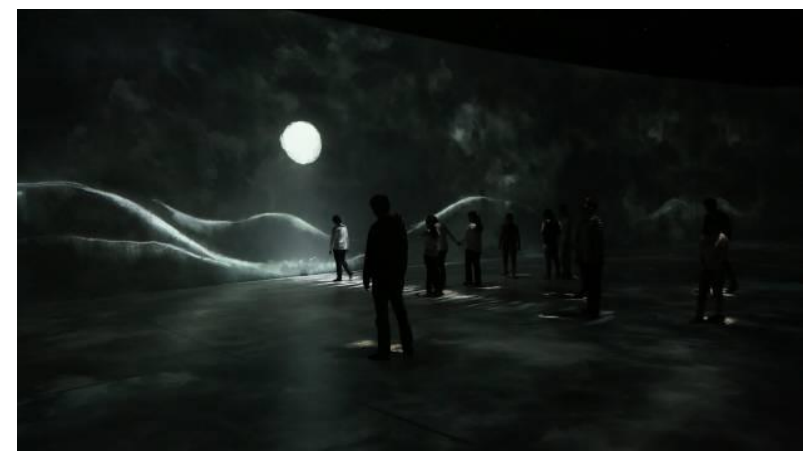

Figure 11: Visitors amidst the exhibition space (C) Tamschick Media+Space)

To this end, the immersive interactive multi-media installation "Time Machine: How great Helü is!" was conceived. In a space measuring more than 400 sqm, visitors can experience a 15 -minute long, historically correct narrative telling the story of the rise of the kingdom of $\mathrm{Wu}$ in eleven chapters. The entire process - from the development of the story until the detailed design phase - has been supervised by Prof. Zhang, historian and expert for the history of the greater Shanghai-region. The films visual style is inspired by traditional Chinese watercolour paintings.

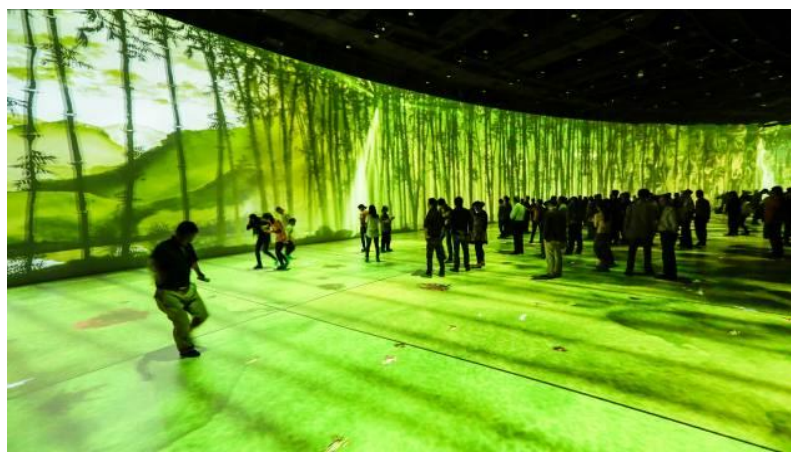

Figure 12: Wide view of the exhibition space with a group of visitors (C) Tamschick Media+Space)

The whole room is designed only for the "Time Machine": its basic layout has the shape of a pie slice. The front wall, used as the main projection surface, is almost $30 \mathrm{~m}$ wide and is slightly bend. The side walls are fully covered with mirrors, creating the impression of a circular space. Thus, already through its physical design the spaces boundaries are dissolved. Additionally to the big front wall, the whole floor is covered with video projections. By these means even the remaining indications for boundaries of the built space can be superimposed and altered through media.

The basis for the staging is a 15-minute-long linear narrative. The visitors stand amid the projection. All their movements in the space are tracked, computed and translated into graphics, which in return are superimposed over the linear film layer. In some moments, visitors can interact with concrete objects. This happens mostly in moments, when the narrative allows letting the visitors become part of the narrative through interaction with the objects. In other scenes unobtrusive, abstract graphics enfold each person in the space, enabling them to fully focus on the narrative displayed on the front wall. The visual layer is supported by a narrator and a 36-channel soundcomposition referencing traditional Chinese music.

The different measures described above dissolve the spatial boundaries in the perception of visitors. The media-based world is coming to the fore and incorporates the visitors entirely. Through this intense experience, that is both sensual and bodily, visitors get a direct access to the narrative. As this installation is designed to work with a large group of people (the museum restricts access to 100 people at a time), the "Time Machine" is also providing a group experience. During the many runs the author has witnessed, people talking about the fine details of the images or playing with the interactive elements together. Research on the actual effectiveness of this large-scale mediabased group experience is yet to be done. 


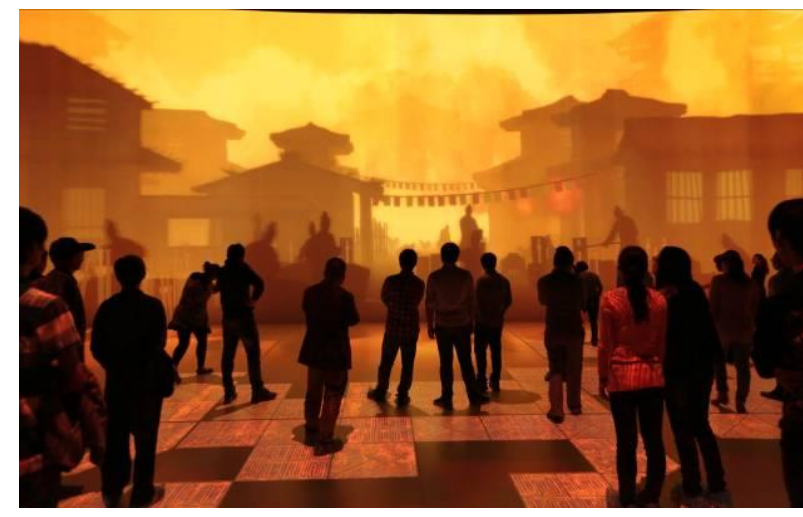

Figure 13: Detail of the space and the video projection with group of visitors

(C) Tamschick Media+Space)

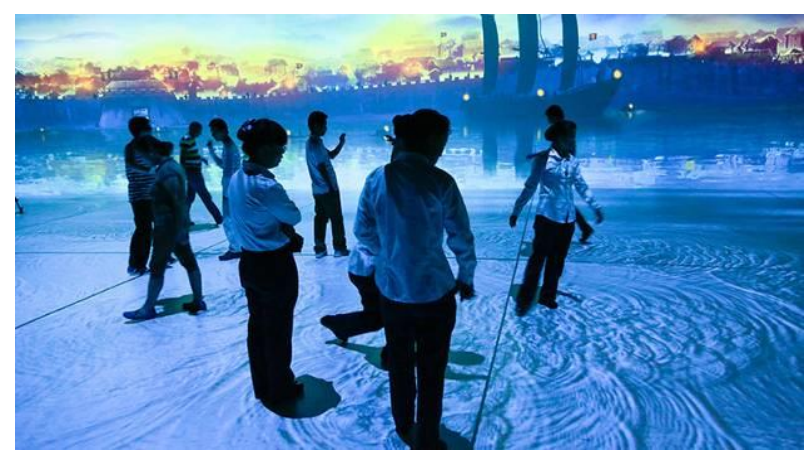

Figure 14: Detail view of visitors interacting with "digital" water ripples (@ Tamschick Media+Space)

\subsection{Discussing Technology \& Democracy - Norwegian Museum of Technology, Oslo (Norway)}

On the occasion of the centennial of the Norwegian Museum of Technology (and at the same time the 200th birthday of the Norwegian constitution) its curators wanted to create a jubilee exhibition dealing with the complex relationship of "Technology" and "Democracy" - how do (historic and present) technologies influence democratic societies and what is their significance. From this basic task further questions derived. What are the requirements for an exhibition dealing with such a complex subject matter? How can visitors get access to this? How can a relationship to a notgraspable thing like "Democracy" be "put on display"?

To cope with the aforementioned challenges, Ralph Appelbaum Associates and TAMSCHICK MEDIA+ SPACE developed in close cooperation with the museums curators a new exhibition format.

At its core, the exhibits and the media-based scenography form the framework for a discursive space with the visitors as an integrative part. Through debates and discussion amongst them, visitors should explore and discover their own thoughts or ideas they have with regard to the subject matter and determine what level of relevance they ascribe to certain "facts".

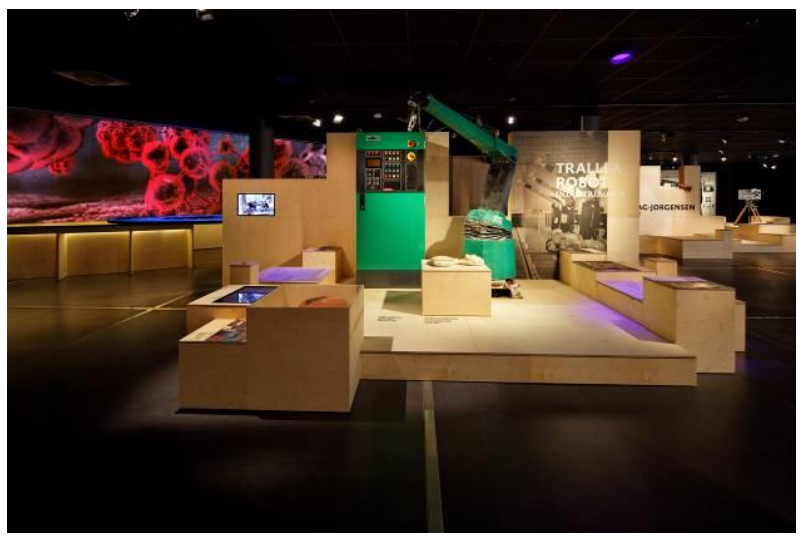

Figure 15: View of the exhibition space with introductory part in the foreground and the media-based TING in the back (@ Manfred Vogel)

The core is the so-called TING. Its name and functionality derive directly from the ancient Thing the governing assembly in villages and boroughs in northern Europe, which happened mostly at a circular place with a big stone at its centre. People gathered around the stone to discuss and decide current questions and "things".

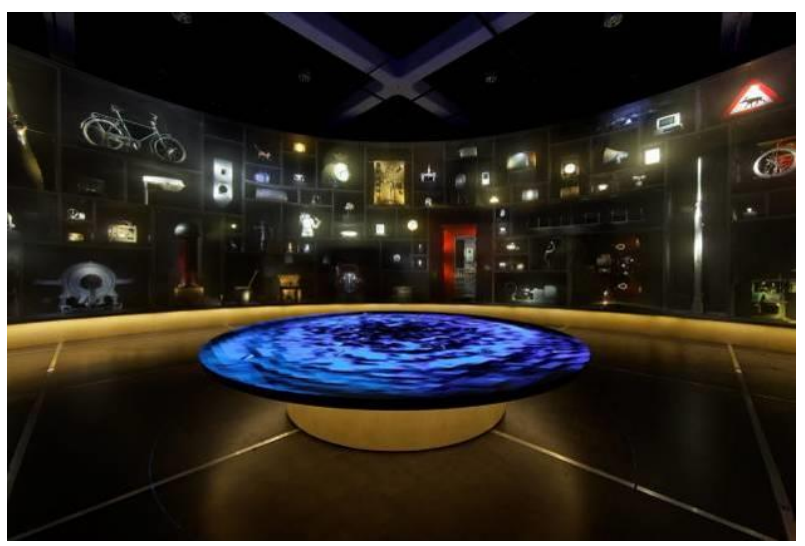

Figure 16: Central interactive table with surrounding shelf displaying the 100 objects (@ Manfred Vogel)

For the exhibition, a media-based TING has been developed. Visitors gather around a circular, interactive augmented table. They are surrounded by a semi-circular, larger-than-life sized shelf containing 100 selected objects. A gauze, which was installed in front of it, served as 180 degree projection surface through which the objects behind were still visible when there is no content displayed. Surrounding the table several benches with integrated tablet-computers emphasise the circular shape of the space and allow either one-ata-time interaction or simply provide a place to watch the discussion. Multiple visitors at a time can retrieve information on the different objects in the shelf by placing wooden cubes (resembling the 
digital pixel) on the table on projected images of the objects.

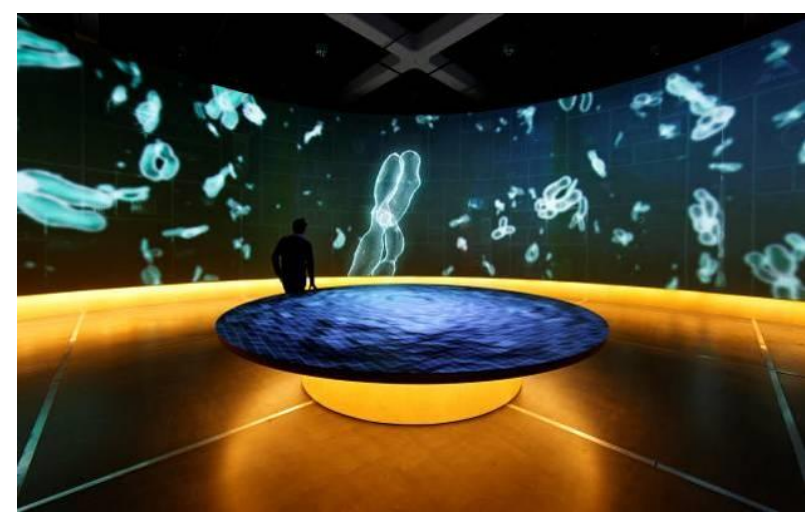

Figure 17: Central interactive table with surrounding shelf functioning as immersive projection surface

(C) Manfred Vogel)

But the cores of the concept are the so-called TING sessions that are held at regular intervals throughout the day. From a group of eight, one technology is put into the TING for discussion. At the beginning an immersive filmic narration looks at aspects of its past and current influence and raises questions about the future impact on democracy and society.

This is followed by a discussion which is normally led by a moderator. Starting point are five controversial questions that point to different aspects. Each question can be answered with yes, no or undecided. Again, the main interface for participating in the poll is the table, but also visitors standing outside the centre can participate through using the tablets. The answer of each visitor is clearly visible and the overall results are displayed on the big projection screen. The moderator uses the visualisation to discuss the motivation for their votes with the visitors and to stimulate a discussion amongst them. After the last question, the overall results as well as historic results (accumulated over the course of the exhibition) are visualised. At the end, visitors are invited to leave their opinions and thoughts on the topic via their Smartphones or the tablet computers. Being directly visible, these diverse comments accumulate to a big stream of opinions.

The media-based scenography and the exhibition design are the framework for the discursive social space of the TING. The introduction films give an overview on the topic and help visitors to get into the complex topics. Through participating (or watching) the following discussions, they can look at the inherent aspects from different angles and are encouraged to form their own opinions. Although the starting points of this exhibition are original objects, the main exhibit is a process that invites visitors to contemplate about almost philosophical relationships.

contemporary questions

and

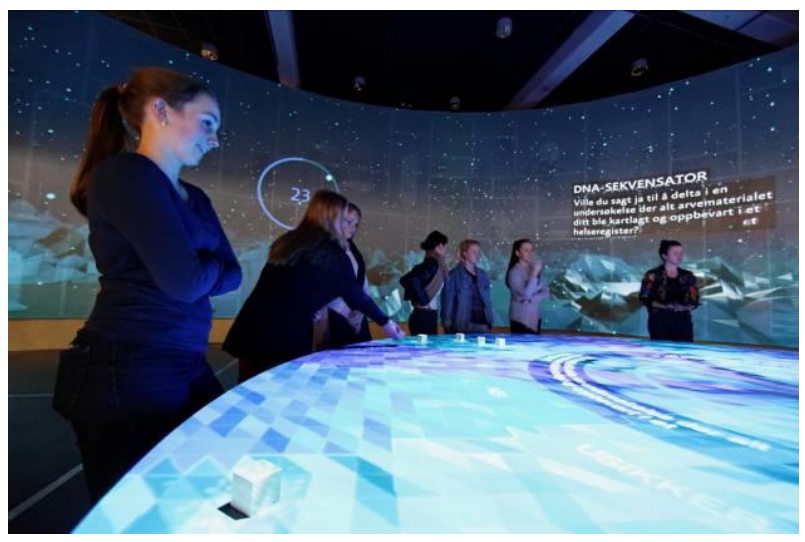

Figure 18: Visitors at the TING table during a session discussing the DNA sequencing technology (C) Manfred Vogel)

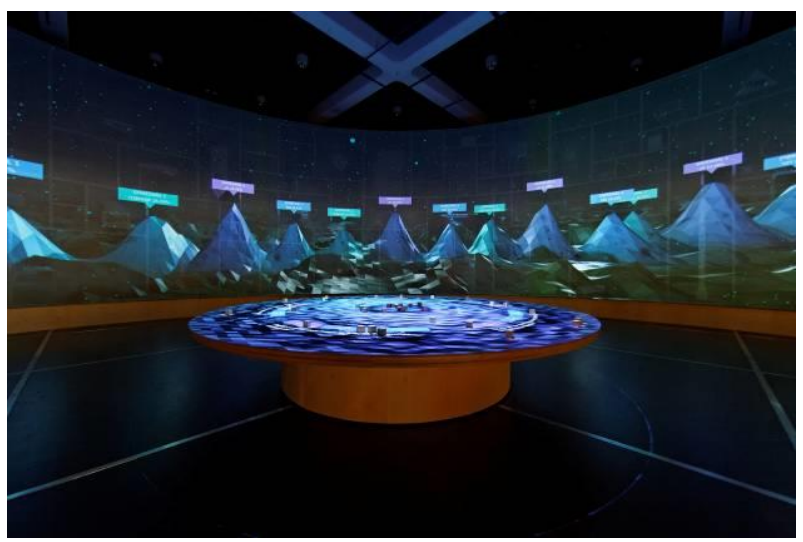

Figure 19: Real-time visualisation of the voting results (C) Manfred Vogel)

Earlier critics have stated that interaction based exhibitions bear the danger of focussing too much on one-person-at-a-time experiences disregarding the power of a group-based collaborative experience (Heath \& v. Lehn 2004, Heath \& v. Lehn 2009). But at the TING, the group-experience is the starting point, enabling visitors to form their opinion through discussion. Ideally, the intense thinking processes evoked by the visit to the exhibition last longer and lead visitors to question certain technologies they have taken as granted so far. Following v. Lehn \& Heath (2002), visitors that participated in the TING have a more profound experience of the exhibition as they have been actively involved in the process of mediating the information.

But first experience from the museum shows, that the moderator is a fundamental part to guarantee an enduring and sustainable experience. He/she fosters the discussion and leads the visitors out of their comfort zones. 


\section{CONCLUSIONS}

The aforementioned examples show different ways how both linear and interactive audio-visual media can be utilised in museums and exhibitions. In their combination they can make multiple levels of information and meaning accessible and provide a deeper look into the respective topics. Together with an immersive staging they can transform spaces and build the framework for a metaphorical or discursive space. Disregarding the use cases it is important to mention that the different media should never be used as ends in themselves. The particular usage should always derive from the topic or concept. Only through using audio-visual media installations in a conscious way, they can be effective in enhancing the experience.

Most of the time, the artists and creators are done with their jobs once the final project is handed over to the client. But an ongoing research with a holistic approach, i.e. considering all involved disciplines, on how the audience is actually experiencing projects like the ones discussed above is missing so far. When it comes to evaluating audio-visual linear or interactive installations, experts from different fields are necessary to support the curators in their research.

Experience shows that it is of great importance that experienced, creative and brave curators, scenographers \& media designers need to work in close collaboration towards an exhibition that makes use of all tools that are needed to meet the individuals' aims of each project and create a unique experience.

\section{REFERENCES}

Heath, C. \& v. Lehn, D. (2004) Configuring reception: (Dis-)Regarding the 'spectator' in museums and galleries. Theory Culture and Society, 21(6), 43-65.

Heath, C. \& v. Lehn, T. (2008) Configuring 'Interactivity': Enhancing Engagement in Science Centres and Museums. Social Studies of Science, 38(1), 63-91.

Heath, C., \& v. Lehn, D. (2009). Interactivity and Collaboration: new forms of participation in museums, galleries and science centres. In R. Parry (ed.), Museums in a Digital Age. Routledge, Milton Park, pp. 266-280.

Koehne, E. (2015) Culture Communication between Science and Media Art. In M. Tamschick \& C. Tamschick (eds.), TAMSCHICK MEDIA+ SPACE - Immersive narrative Installations, AV Edition, Berlin.

v. Lehm, D. \& Heath, C. (2002) Das Museum als Lern- und Erlebnisraum. 31. Kongress der Deutschen Gesellschaft für Soziologie 2002, Leipzig, Germany, Leske + Budrich, Opladen, Germany.

Merriam-Webster (n.d.) Shrovetide. Dictionary. http://www.merriam-webster.com/dictionary/ Shrovetide (retrieved 15 March 2015).

Ventimiglia, T. (2015) Technology and Democracy on Discussion. In Tamschick, M., \& Tamschick, C. (eds.). TAMSCHICK MEDIA+SPACE - Immersive narrative Installations, AV Edition, Berlin.

Vieregg, H. K. (2006) Museumswissenschaften. Eine Einführung, Fink, Paderborn.

Waidacher, F. (2004) Museologie knapp gefasst. Mit einem Beitrag von Marlies Raffler. Unter Mitarbeit von Marlies Raffler, Boehlau, Wien, Koeln, Weimar. 